\author{
УДК 681.121 .089
}

DOI: 10.31471/1993-9981-2018-2(41)-77-81

\title{
ЕКСПЕРИМЕНТАЛЬНЕ ВИЗНАЧЕННЯ ЕКВІВАЛЕНТНОГО КОЕФІЦІЄНТА ТЕПЛОПРОВІДНОСТІ
}

\author{
${ }^{1}$ M. R. Rzasa*, ${ }^{2}$ O. E. Середюк \\ ${ }^{1}$ Політехніка Опольська, вул. Миколайчука, 5, 45-271 м. Ополе, Польща \\ ${ }^{2}$ Івано-Франківський національний технічний університет нафти і газу, вул. Карпатська, 15, м. \\ Івано-Франківськ, Україна, 76019; тел.(0342)72-71-68,mivt@nung.edu.иа
}

The coefficient of thermal conductivity as one of heat transfer parameters is investigated. This option is cataloged for most building materials. This makes it easy to determine the amount of heat transmitted through the building mantle. It is much more difficult to calculate the amount of heat transferred for premises, the walls of which are made of different materials, which makes their heat conducting surfaces heterogeneous. In addition, the calculation is complicated when the temperature along the surface is non-uniform. The definition of the equivalent heat conduction coefficient for a certain camera is proposed. The coefficient of equivalent heat conductivity allows to calculate the value of the transferred heat by multiplying it by the total surface area of the camera walls. An experimental method for determining the equivalent coefficient of thermal conductivity is proposed. A theoretical analysis of the determination of the error of the equivalent thermal conductivity coefficient based on the uncertainty theory in the measurements is carried out search, thermal conductivity, equivalent thermal conductivity coefficient, standard uncertainty.

Keywords: heat transfer coefficient, experimental research, thermal conductivity, equivalent thermal conductivity coefficient, standard uncertainty.

Досліджується коефіцієнт теплопровідності як один із параметрів теплопередавання. Цей параметр є каталогізованим для більшості будівельних матеріалів. Це дозволяє легко визначити кількість тепла, що передається через будівельне перекриття. Набагато важче обчислити величину переданого тепла для приміщень, стінки яких виготовлені 3 різних матеріалів, що робить теплопровідність їх поверхні неоднорідною. Крім того, розрахунок ускладнюється, коли температура вздовж поверхні є неодиниковою. Запропоновано визначення еквівалентного коефіцієнта теплопровідності для окремої камери. Коефіцієнт еквівалентної теплопровідності дозволяє розраховувати значення переданої теплоти шляхом множення іiі на загальну площу поверхні стін камери. Запропоновано експериментальний метод визначення еквівалентного коефіцієнта теплопровідності. Проведено теоретичний аналіз визначення похибки еквівалентного коефіцієнта теплопровідності на базі теорії невизначеності у вимірюваннях.

Ключові слова: коефіцієнт теплопередачі, експериментальні дослідження, теплопровідність, еквівалентний коефіцієнт теплопровідності, стандартна невизначеність.

Исследуется коэффициент теплопроводности как один из параметров теплопередачи. Этот параметр каталогизирован для большинства строительных материалов. Это позволяет легко определить количество тепла, передаваемого через строительную перегородку. Гораздо труднее вычислить величину передаваемого тепла для помещений, стенки которых изготовлены из различных материалов, что делает теплопроводность их поверхностей неоднородной. Кроме того, расчет усложняется из-за неравномерности температуры по поверхности стенки. Предлагается эквивалентный коэффициент теплопроводности рассчитывать для определенной камеры. Коэффициент эквивалентной теплопроводности позволяет рассчитывать значения передаваемой теплоты путем умножения ее на общую площадь поверхности стен камеры. Предложен экспериментальный метод определения эквивалентного коэффициента теплопроводности. Проведенный теоретический анализ определения погрешности эквивалентного коэффициента теплопроводности по теории неопределенности в измерениях.

Ключевые слова: коэффициент теплопередачи, экспериментальные исследования, теплопроводность, эквивалентный коэффициент теплопроводности, стандартная неопределенность. 
Вступ. У холодильних системах дуже популярні компресорні чилери $[1,4]$. Цей тип розчину застосовується в системах 3 прямим теплообміном 3 охолодженого повітря (компресійно-конденсаційних агрегатів), а також у системах 3 проміжною рідиною (агрегати охолоджуючої води) [2]. На практиці використовуються різні типи компресорних установок, в яких теплота конденсації може передаватися в навколишнє середовище або використовуватися корисним способом [3]. На ефективність роботи всього холодильного агрегату значно впливає регулювання його ок ремих компонентів. На це впливає не тільки ефективність холодильної установки, яка визначається коефіцієнтом КП (коефіцієнт продуктивності), але і якість теплової ізоляції холодильної камери. Одним 3 основних параметрів, що впливають на кількість тепла, що надходить від навколишнього середовища через стінки холодильної камери, є коефіцієнт теплопровідності. Цей параметр каталогізований для більшості будівельних матеріалів. Це дозволяє дуже легко визначити кількість тепла, що проходить крізь стінку. Набагато складніше розрахувати величину проведеного тепла для приміщень, стінки яких виготовлені з різних матеріалів, що призводить до того, що їхні провідні поверхні не $\epsilon$ однорідними. Крім того, розрахунок ускладнює це, коли зовнішні температури на поверхні камери не збігаються. Запропоновано визначення еквівалентного коефіцієнта теплопровідності для даної камери. Коефіцієнт еквівалентної теплопровідності дозволяє розрахувати значення проведеної теплоти шляхом множення іiі на загальну поверхню стін камери.

$$
Q=\lambda \cdot A \cdot \Delta T_{s},
$$

де: A - площа стінки контейнера, equivalent еквівалентний коефіцієнт теплопровідності [W/ $(\mathrm{m} 2 \mathrm{~K})], \Delta T_{s}$ - різниця температур всередині і зовні камери в обраному місці. Запропоновано експериментальний метод визначення еквівалентного коефіцієнта теплопровідності.

Дослідницький стенд. Для потреб дослідження було побудовано вимірювальний стенд, основним елементом якого була холодильна установка 3 інверторним компресором потужністю 480 Вт, що постачалася 3 напругою 48В постійного струму. Завдяки такому рішенню можна було регулювати потужність компресора, змінюючи значення напруги живлення. Випробувальний стенд також включає вимірювальну камеру $(\mathrm{V}=$ 12,41 м3), яка була виготовлена зі сталевого промислового контейнера. Контейнер поміщали у вільний простір за атмосферних умов, що дозволяло спостерігати за роботою випробуваного агрегату в умовах, аналогічних його природним умовам експлуатації. Всередині камери знаходиться бак, заповнений 0,75 м3 води. Резервуар для води виконував роль акумулятора теплової енергії, імітуючи матеріал, підданий охолодженню. Вимірювальний стенд був обладнаний системою збору даних вимірювань, підготовленої в середовищі LabView, що дозволило постійно контролювати i записувати ряд фізичних параметрів під час тестування.

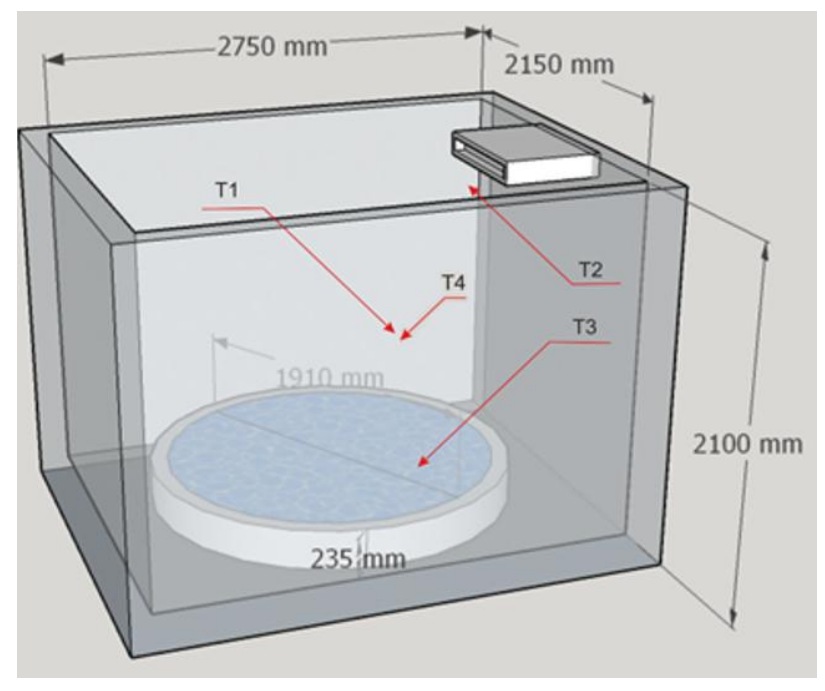

Рисунок 1 - Дослідницький стенд

Камера має ряд датчиків температури, підключених до системи збору даних. Датчик Т3 був поміщений в резервуар для води для запису змін температури, на основі яких була визначена кількість енергії, отриманої холодильним агрегатом 3 резервуара. Також датчик Т2 вимірював температуру повітря в камері. Потужність, отримана від води та повітря, розраховується за формулами

$$
\begin{gathered}
P_{w}=V_{w} \cdot \rho_{w} \cdot c_{w} \cdot \frac{d T_{w}}{d t}, \\
P_{p}=V_{p} \cdot \rho_{p} \cdot c_{p} \cdot \frac{d T_{p}}{d t},
\end{gathered}
$$


де: Vw, Vp - об'єм води і повітря [m3], щільність води і повітря [кг / м3], cw, сp питома теплота води і повітря [J / кгK], Tw, Tp температура вода і повітря [K], - час [h].

Результати досліджень. Результати вимірювання температури для частоти обертання компресора 3750 об / хв наведені на рис. 2. Наведені характеристики не включають результатів, отриманих від датчика Т2, розміщеного всередині камери, оскільки температура повітря всередині камери лише незначно відрізнялася від температури води в резервуарі.

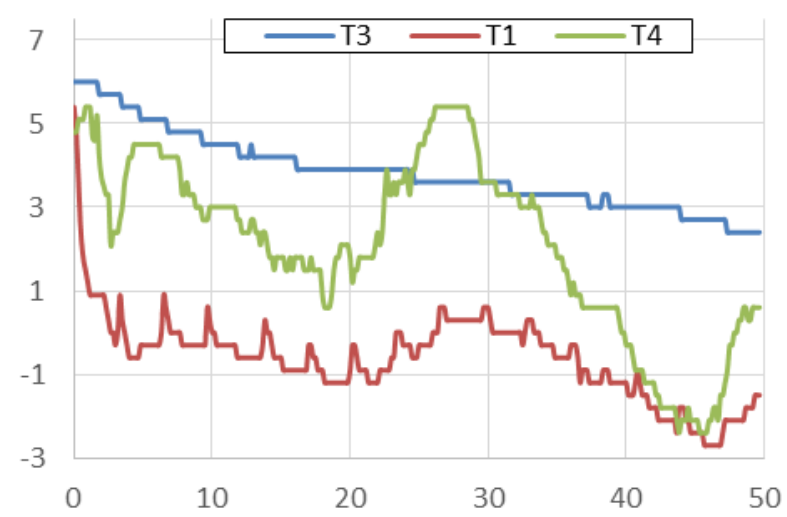

Рисунок 2 - Температурні характеристики процесу охолодження.

За температурними характеристиками визначаються значення градієнта температури в холодильній камері та різниця температур на стінці камери.

Визначення еквівалентного коефіцієнта теплопровідності. Для визначення еквівалентного коефіцієнта теплопровідності для холодильної камери необхідно провести енергетичний баланс. Основними джерелами енергії в розглянутій системі $\epsilon$ : теплова потужність, отримана 3 резервуара для води, теплова потужність, отримана 3 повітря, що заповнює вимірювальну камеру, i теплова потужність, що проходить через стінки камери. На цій базі визначено рівняння енергетичного балансу

$$
P_{\alpha}=P_{w}+P_{p}+Q .
$$

Значення потужності, що надходять 3 резервуара для води, і потужність, отримана від повітря, що заповнює камеру, розраховуються за виміряною температурою за формулами (2) i
(3). Потужність, що передається через стінки холодильної камери, обчислюється за формулами провідності(1).

a)

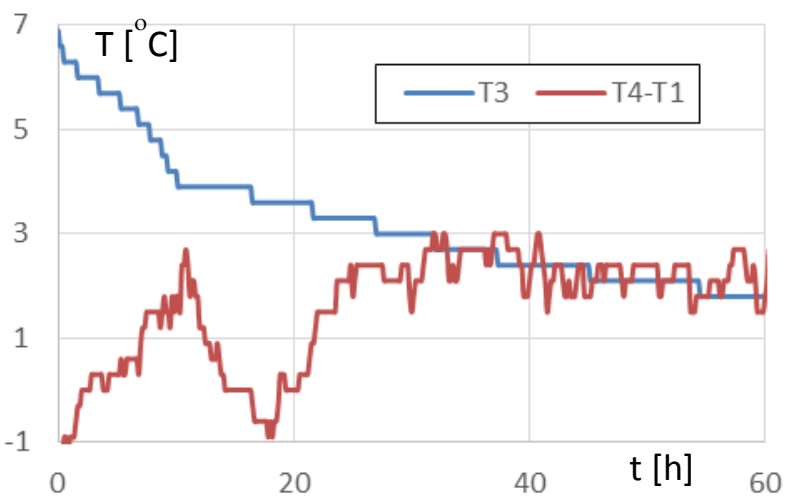

b)

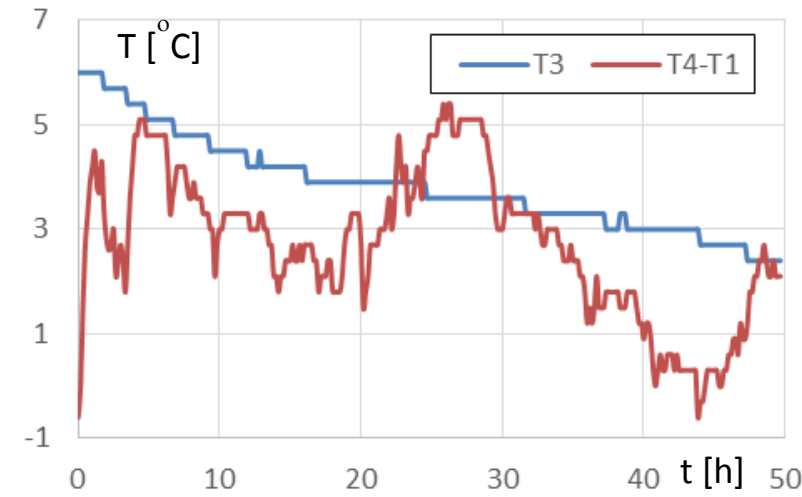

c)

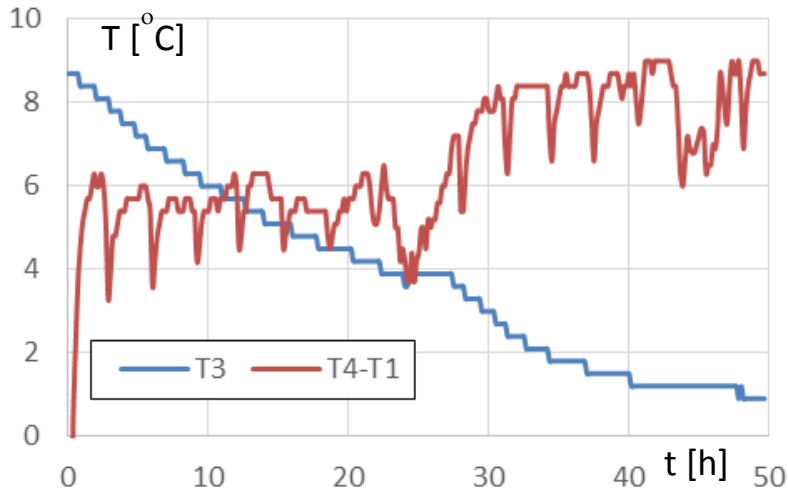

Рисунок 3 - Температурні характеристики холодильного агрегату а) при $n=3120$ об $/$ хв b) при $n=3750$ об $/$ хв с) при $n=43500$ об $/$ хв

Значення еквівалентного коефіцієнта провідності визначали на основі серії вимірювань. На рис.3 наведено приклади температурних характеристик процесу охолодження 3 урахуванням різниці температур на стінці камери. Було зареєстровано кілька характеристик для різних частот обертання 
компресора. Таке рішення дозволяє зменшити вплив швидкості охолодження на усереднене значення коефіцієнта теплопровідності. Швидкість обертання компресора регулювалася в діапазоні від 3000-4400 об / хв. Крива Т3 на малюнку 5 показує зміну температури води під час процесу охолодження. 3 цієї характеристики зчитувався градієнт температури охолодженої води. Оскільки цей градієнт не є постійним у всьому діапазоні вимірювань. Для розрахунку приймалися значення 3 декількох годинного інтервалу часу, для яких величина різниці температур на стінці камери була відносно постійною. Характеристика зміни різниці температур між датчиками Т1 і Т4 є основою для розрахунку коефіцієнта теплопровідності, що випливає з рівняння Фур'є.

На основі характеристик, наведених на рисунку 3, були визначені чотири часові інтервали, в яких переважали стабільні умови. Той факт, що умови стабільні, свідчить про те, що протягом декількох годин відмінності і температури на стінці камери суттєво не змінюються при рівному зниженні температури охолодженої води. Потім для цих відділень визначали температурні градієнти охолодженої води i зчитували середнє значення різниці температур на стінці вимірювальної камери. Виходячи 3 градієнтів температури води, розраховані потужності, зібрані як з води, так і 3 заливки камери. Результати вимірювань i розрахунків представлені в таблиці 1.

Таблиця 1. -Результати розрахунків

\begin{tabular}{|c|c|c|c|c|c|}
\hline № & Чac [h] & $\begin{array}{c}T 4-T 1 \\
{[\mathrm{o} C]}\end{array}$ & $\begin{array}{c}T \\
{\left[{ }^{0} \mathrm{C}\right]}\end{array}$ & $P_{w}[W]$ & $P_{p}[W]$ \\
\hline 1 & $42-55$ & 2,1 & 0,52 & 34,74 & 0,16 \\
\hline 2 & $30-35$ & 8,1 & 1,2 & 208,45 & 0,94 \\
\hline 3 & $14-20$ & 2,4 & 0,3 & 43,43 & 0,02 \\
\hline 4 & $41-46$ & 0,3 & 0,3 & 52,11 & 0,24 \\
\hline
\end{tabular}

Для визначення середнього значення коефіцієнта теплопровідності вважалося, що коефіцієнт теплопровідності $є$ постійним і не залежить від способу охолодження. На основі цього припущення можна записати наступне рівняння енергетичного балансу:

$$
\mathrm{P}_{\mathrm{w} 1}+\mathrm{P}_{\mathrm{p} 1}+\mathrm{Q}_{1}=\mathrm{P}_{\mathrm{w} 2}+\mathrm{P}_{\mathrm{p} 2}+\mathrm{Q}_{2}
$$

Індекси 1 і 2 відносяться відповідно до обраних часових інтервалів. На підставі даних, наведених у табл. 1, можна організувати шість незалежних рівнянь, які обчислюють шість значень коефіцієнта провідності після перетворення рівняння (5) i заміщення залежностей (2), (3) і (1). Формула коефіцієнта теплопровідності має такий вигляд:

$$
\lambda=\frac{\mathrm{P}_{\mathrm{W} 2}-\mathrm{P}_{\mathrm{W} 1}+\mathrm{P}_{\mathrm{p}_{2}}-\mathrm{P}_{\mathrm{p} 1}}{\mathrm{~A}\left(\mathrm{~T}_{1}-\mathrm{T}_{2)}\right.} .
$$

Результати розрахунків для різних комбінацій точок наведено на рис. 4. Більшість отриманих результатів подібні до величини $\lambda=$ 0,89 Вт / (м2К). Значення для пунктів 5 і 6 не будуть враховані при подальших розрахунках, оскільки вони були класифіковані як грубі помилки. Причиною їх створення $є$ невеликі відмінності в значеннях потужності i температури, що використовуються для розрахунку коефіцієнта теплопровідності.

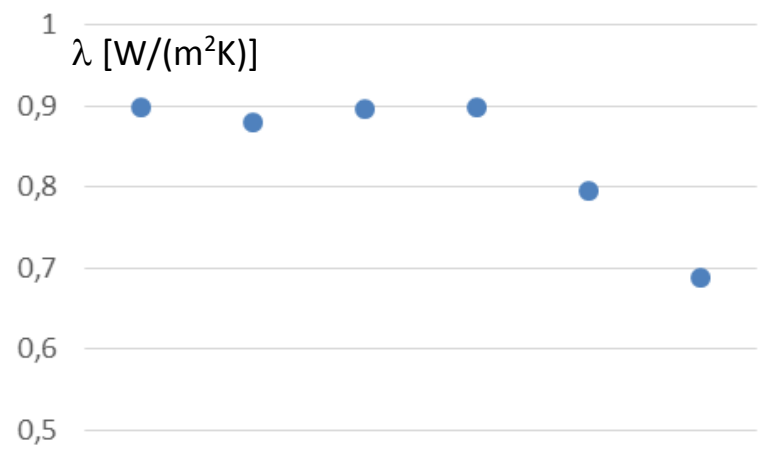

Рисунок 4 - Розрахункові значення еквівалентного коефіціснта теплопровідності

Стандартну невизначеність коефіцієнта еквівалентної провідності розраховували за формулою

$$
U_{\lambda}=\sqrt{\frac{\left(\bar{\lambda}-\lambda_{i}\right)^{2}}{N(n-1)}},
$$

де: $\lambda^{-}$- середнє арифметичне значення коефіцієнта провідності, а $\lambda_{\mathrm{i}}$ - значення окремих компонентів. Невизначеність після розширення до довірчого інтервалу $\mathrm{p}=95 \%$ склала $\mathrm{U}=0,98$ Вт / (м2К). Цей результат може вважатися задовільним i достатнім для інженерних додатків. 
Висновок.

У роботі розглянуто метод визначення еквівалентного коефіцієнта теплопровідності. Цей метод дозволяє визначити еквівалентний коефіцієнт теплопровідності для складних об'єктів, таких як холодні приміщення. Точність визначеного коефіцієнта достатня для більшості інженерних додатків. Метод не вимагає складних розрахунків і може бути використаний для об'єктів 3 різними зовнішніми температурами. Застосування методу особливо зручне у випадку, коли охолоджуюча камера розміщується на підлозі, де температура значно відрізняється від температури навколишнього середовища, або в умовах, коли частина камери нагрівається променями сонця, а інша частина камери знаходиться в затіненому місці. Впровадження деяких спрощень при визначенні еквівалентного коефіцієнта теплопровідності не призводить до суттєвих помилок, про що свідчить невизначеність на рівні $10 \%$ від розрахункового значення. Представлене рішення може стосуватися для вивчення складних холодильних систем i оцінки споживання електроенергї цими системами.

1.Adamski B.: Nowoczesne rozwiazania $w$ zakresie sprężarkowych agregatów chłodniczych, Rynek Instalacyjny 10/2006, Warszawa, 2006.

2.Mu, B., Li, Y., House, J. M., \& Salsbury, T. I. : Real-time optimization of a chilled water plant with parallel chillers based on extremum seeking control. Applied Energy, 208, 2017.

3.Park, Y. S., Jeong, J. H., \& Ahn, B. H. .: Heat pump control method based on direct measurement of evaporation pressure to improve energy efficiency and indoor air temperature stability at a low cooling load condition. Applied energy, 2014.

4.Wang, B., Liu, X., \& Shi, W.: Performance improvement of air source heat pump using gasinjected rotary compressor through port on blade. International Journal of Refrigeration, 73, 2017.

Поступила в редакцію 01.12.2018 р. Рекомендували до друку: докт.техн.наук, проф. Райтер П. М. докт. техн. наук, проф. Горбійчук М. I. 